Pak. j. sci. ind. res. Ser. A: phys. sci. 2020 63A(3) 201-208

\title{
Assessing the Serviceability Status of Existing Transport Network by Using Geospatial Techniques in Metropolitan City Lahore
}

\author{
Syeda Jabeen Fatima*, Muhammad Asif Javed and Sajid Rashid Ahmed \\ College of Earth and Environmental Sciences, University of the Punjab, Lahore, Pakistan \\ (received August 15, 2018; revised May 21, 2019; accepted June 25, 2019)
}

\begin{abstract}
Reliable and an efficient Public Transport plays key role in establishing sustainable Urban Transport system and healthy environment in any city. Public Transport equity in terms of easy access for the commuters is very crucial. With the drastic increase in population and cities extent in developing countries like Pakistan, the travel demand is recklessly increasing which urge to provide efficient public transit which may cater the ever increasing transport demand. Lahore being the provincial capital of Punjab and the second most densely populated city of Pakistan, has a remarkably large transportation network. The case study presented an advanced approach to determine the population with walking access to transit stop of Lahore Public Transport network, by using Geographical Information System (GIS). This approach is quite efficient, reliable and helpful to investigate the effectiveness of transit network, user's access to transit stops and spatial gaps in the transit facilities. GIS-based network service area analysis has been utilized to find the transit stop service area of the existing public transport network in metropolitan city Lahore. To find the transit stop service area, suitable walking time of $8 \mathrm{~min}$ or threshold distance of $624 \mathrm{~m}$ with walking speed of $78 \mathrm{~m} / \mathrm{min}$ has been used as a standard. Transit stop service area has been used to find the population with walking access to a transit stop. The results reveal that only $40 \%$ of the total population was in suitable walking distance, which shows that less serviceability is due to the improper spatial distribution of existing transit stops across the transit route. The results also identify the population which is not in suitable walking distance to transit service. This study concludes that Geospatial Techniques are significant in assessment of the effectiveness and subsequently measuring the gaps in the existing transport network. Thus, on the basis of these results sustainable solution would be presented to enhance the efficacy of the integrated public transport.
\end{abstract}

Keywords: accessibility, service area analysis, GIS, transit stops, spatial distribution

\section{Introduction}

Public Transport (PT) has been considered as a significant means of social and sustainable transportation system, which may improve the quality of urban life Mamun (2011). Transport accessibility caters the urban growth and key factor for enhancing the sustainability in urban areas Ford et al. (2015). To enhance the social and economic performance of urban areas, it is necessary to provide good and effective connectivity between resources and destinations. There is a dire need to establish common parameters for transportation analysis among many metropolitan cities with different dimensions and frame works to meet the ever increasing demand for global collaboration towards more sustainable urban structures and environments Bok and Kwon (2016).

In transportation system and analysis accessibility is the most important concept Lei and Church (2010).

*Author for correspondence;

E-mail: jabeenfatima16@yahoo.com
Accessibility may be defined as spatial relation of one location to other specified location Park (2012). Walking access is proximity of the Passenger's origin or destination to the nearest transit stop Foda and Osman (2010). Transit stop accessibility plays a role as catalyst in economic development Van (2011), environmental objectives Grengs (2010) and equitable access for all socio-economic groups Foth et al. (2013). Saghapour et al. (2016) measured the Public Transport accessibility in Melbourne area, Australia by using Public Transport Accessibility Index. He investigated that, there is a higher probability of Public Transport patronage in areas with higher levels of accessibility. EI-Geneidy et al. (2010) determined transit system effectiveness can be achieved by measuring the percentage of population served in the metropolitan region. He also identifies the causes of redundancies and gaps in transport system. Time and service frequency are important factors to users in context of Public Transit Curtis et al. (2010). Service frequency plays a vital role 
driving public transit patronage Wang (2011). It is universally accepted that $400 \mathrm{~m}$ walking distance with mean walking speed between $80-95 \mathrm{~m} / \mathrm{min}$ is the maximum distance a transit user willing to travel to reach their nearest transit stop Biba et al. (2010), while other distances have also been used in urban areas i.e. $300 \mathrm{~m}, 500 \mathrm{~m}$ and $800 \mathrm{~m}$, Mavao et al. (2012).

Urbanization creating a big impact on transportation system in mega cities of Pakistan, Qureshi and $\mathrm{Lu}$ (2007). Urbanization is the key factor in increasing vehicle manufacturing, expansion of road transportation, roads expansion, and it effects the social networking Chai et al. (2016). The abandoned increase in urbanization, motorization and lack of transport planning creates many social, economic and environmental imbalances in city like air pollution, poor transport infrastructure and traffic congestion, which result equity issue Wong (2012). The population in Asian countries is continuously increasing due to which Urban Transport facing worsening conditions. So, urban planners and transport planners should take safety measure to avoid critical transportation problems in future.

This research emphasis on determining the population with walking access to transit stop in conjunction with geometrically corrected pedestrian network, spatially adjusted transit routes and landuse data sets by using GIS based service area analysis. Distances covered by the transit user in accessing the transit stops were used to determine the threshold distances of the transit service area and estimate the population covered by public transport. Suitable walk time of 8 minute or threshold distance of $624 \mathrm{~m}$ with walk speed of $78 \mathrm{~m} / \mathrm{min}$ has been used as a standard to find the transit stop service area.

The study objectives are outline below:

- To develop the robust databases encompassing geometrically corrected network dataset Urban Transport routes, population and land use in study area.

- To investigate the population with walking access to existing transit services in study area using advanced Geospatial approach.

- Identification of the poorly served areas along with potential causes.

\section{Materials and Methods}

Figure 1 shows the material and methods utilized in this study to determine the served population in study area.
Study area. Metropolitan city Lahore has been selected for this study. It is the second most densely populated city in Pakistan and has a remarkably large and complex transportation network. It is situated at Latitude $31^{\circ} 15^{\prime}$ $31^{\circ} 45^{\prime} \mathrm{N}$ and Longitude $74^{\circ} 01^{\prime} 74^{\circ} 39^{\prime} \mathrm{E}$.

The study area comprises of 274 Union Councils (UCs) which cover all existing Public Transport routes and urban population. The outer UCs have comparatively larger area from which $70 \%$ area comprises of an open and undeveloped land, while inner UCs have larger developed areas and maximum number of transit facility. The population of the Lahore city has been estimated about 10 million, with a growth rate of $3.32 \%$ per annum, induces growing city and increasing car ownership. The demand for Public Transport has been increased because large numbers of commuters use Public Transport for migration in different parts of the city. An integrated public transport system was proposed in Lahore to develop sustainable Public Transport system and deal with transportation related issues. Integrated Public Transport network includes HOV (High Occupancy Vehicle) large buses and mass transit, LOV (Low Occupancy Vehicle) mini buses, and Feeder routes that are integrated with high quality BRT systems like Metro and provide access to terminal. According to Lahore Transport Company (LTC), currently, Public

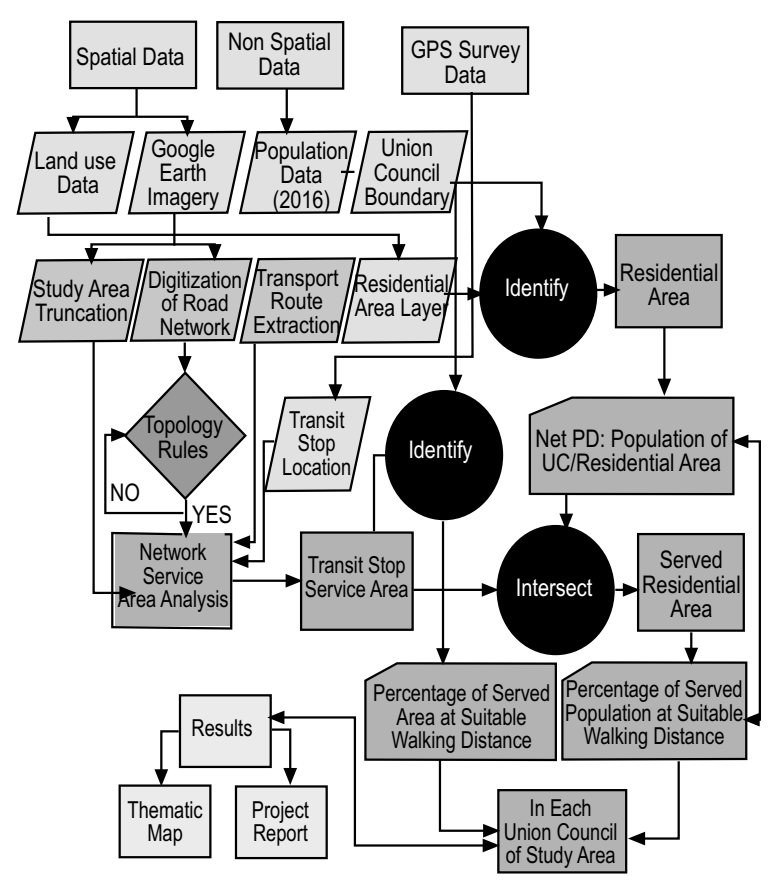

Fig. 1. Working architecture of study area. 
Transport services are providing on 13 operational HOV routes, $22 \mathrm{LOV}$ routes and Metro with integrated 14 operational feeder route.

The prevailing transport situation in Lahore clearly shows that there is a need to develop sustainable and efficient urban Public Transport system to overcome any future transportation related problems. GIS is a power tool that can be applied in travel demand modeling, transportation hazard analysis, finding best route, calculating service area with associated population and for many other transportation analyses. (Biba et al. (2010). Figure 2 depicts the study area map.

Data of the study. The present research has collected a large set of data that later incorporate into GIS to perform Network Analysis. A comprehensive road network data, land use and existing Public Transport data were used in GIS to find out population with walking access of $8 \mathrm{~min}$.

Road network. Detailed road network was digitized on high resolution satellite imagery. Pedestrian/Road network is the essential parameter to measure the accessibility to transit stop. Commuters can access their desire location/transit stop through pedestrian road network surrounding each stop. To develop geometrically corrected network dataset, the edge-node topology was applied on road network data. Geometric errors were removed by applying topological rules prior to use this data in network analyst Javed et al. (2013).

Walking component was developed by using road network data by measuring walk time and length of each road segment. The following simple equation was
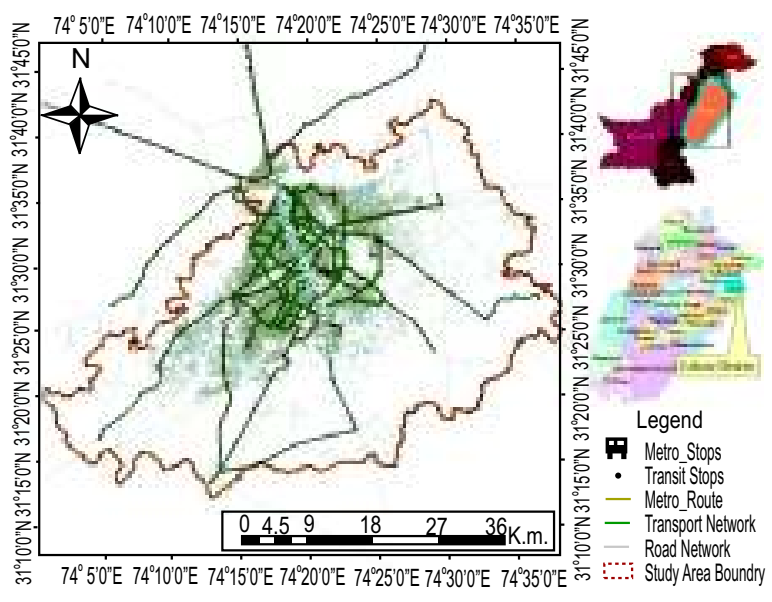

Fig. 2. Study area map. used in ArcGIS 10.3 to develop walking component.

$$
\mathrm{S}=v \times \mathrm{t}
$$

where:

$\mathrm{t}=$ Walk time $(\mathrm{min})$

$\mathrm{S}=$ Length of road segment (meter)

$\mathrm{v}=$ Travel speed (meter per min)

Spatial adjustment of transit data and landuse development. Existing Public Transport route data was acquired form Lahore Transport Company (LTC). Transit data was overlaid on Google Earth satellite image to check the spatial accuracy of data and it was observed that the provided routes were shifted from actual path. The transport network data must be spatially adjusted with road network data to find transit catchment area in Network Analyst. For this purpose, Spatial Analyst tool of ArcGIS has been utilized. Road network curves on the Georeferenced satellite imagery have been used as reference points for spatial adjustment.

Figure 4 illustrate existing Public Transport routes overlay on land-use available in the study area. Gulhan and Ceylan (2016) cited in his research, he determined the transportation investments still stalwartly affect land use patterns, urban masses and housing prices. Interaction

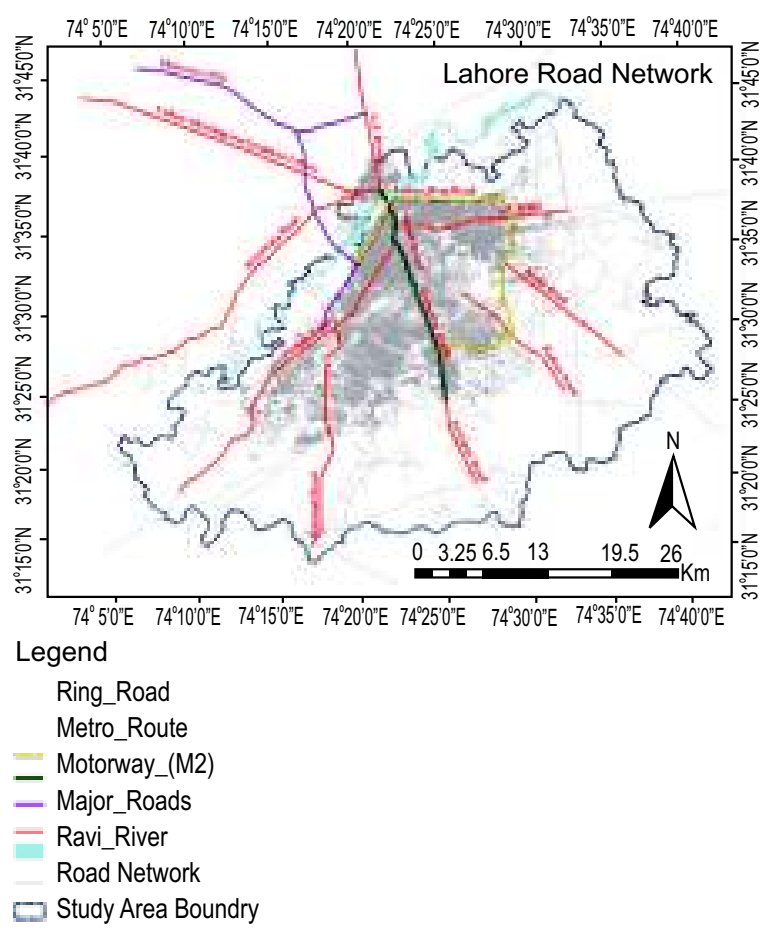

Fig. 3. Road network in study area. 


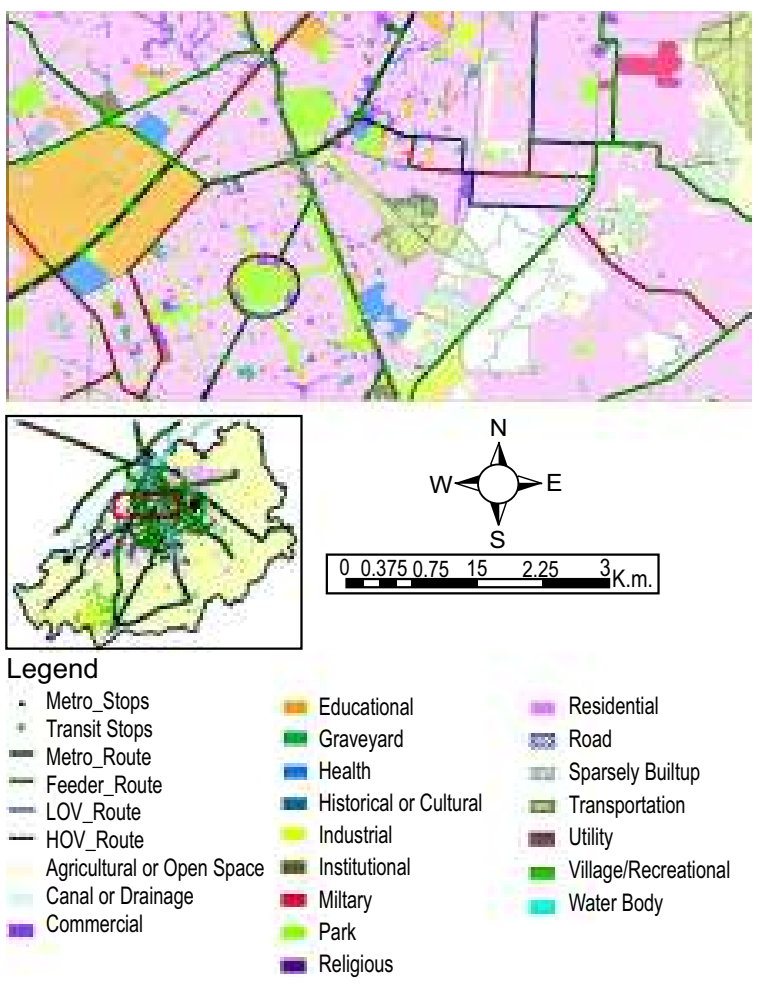

Fig. 4. Existing public transport routes and landuse.

between land use and transportation is the elementary factor for a trip generation.

Network analysis. Identification of areas serviced by public transit. All transit stops have been imported as point features along the pedestrian network. Network dataset must be developed on error free data which have $\mathrm{F}$ node, $\mathrm{T}$ node, $\mathrm{F} \& \mathrm{~T}$ minutes and one-way restriction attributes in Network Analyst. To create Network dataset, it is necessary that all feature classes in the dataset must be connected with each other at every node, it represents the real time network linkage within study area. Area served by Public Transport was created through the Network Analyst Tools of ArcGIS 10.3 using suitable walking time of $8 \mathrm{~min}$ or threshold distance of $624 \mathrm{~m}$ with walking speed of $78 \mathrm{~m} / \mathrm{min}$. It is universally accepted that, suitable walk time of $8 \mathrm{~min}$ is the maximum distance a transit user willing to travel to access their nearest transit stop Finnis and Walton (2008). This service area includes all the streets that can be access within eight minutes from that facility. Once the service areas created, it can be utilized to identify the served population and will help to evaluate accessibility.
Calculation of served population. The results of transit stop service area were further utilized to calculate the population with walking access. Served population has been calculated by overlaying different layers in GIS data framework. Served population is describe by the following formula:

$$
\text { Net population density }=\frac{\text { Total population }}{\text { Total buildup area }}
$$

Served population $=$ Net PD $\times$ served residential area

The effectiveness of transportation system depends on efficient land use decisions and well-arranged residential area densities Handy (2005).

\section{Results and Discussion}

Results evidenced the full capability of GIS based service area analysis to precisely determines the population within a service area of a transit route in Lahore district.

Figure 5 shows the service area of existing public transport routes by taking standardized walk time of $8 \mathrm{~min}$. Result reveal that, irregular service area polygons are due to the unavailability of pedestrian network in study area. The figure depicts that, service area polygon of some transit stops is getting overlapped with service area polygon of other transit stops, which shows the improper spatial distribution of transit stops. Ammons (2001) investigates the reasons for overlapping of transit service area and find that transit stop spacing typically ranges from 656 to 1,968 feet in urban area which is such a small distance between two stops. This small distance creates overlapping zone between stop service areas on the same route as well as stops of adjacent route. Transit stops should be spaced to minimize walking distances in areas which have high public transport demand and to reduce the number of bus stoppages. Transit user density can be increased by providing spatially well distributed transit stops (Foda and Osman, 2010).

Figure 5 shows that transit stops are more closely concentrated in the central and southwest union councils (UCs) providing comparatively good serviceability status in district. On the other hand, transit stops are sparsely distributed in west and northeast Union Councils (UCs) resulting in low or poor serviceability in district.

The results reveal that, population is partially served by existing public transport in the study area. Figure 6 
depicts that, central and southwest union councils (UCs) have comparatively good serviceability due to adequate and spatially well distribution of transits stops. On the other hand, west and northeast union councils (UCs) have low or poor serviceability due to less/null transport facilities. Most of the union councils (UCs) does not have any transit stops despite of having sufficient residential area and public transport demand.

Table 1 depicts the UC wise serviceability status in study area. Only $40 \%$ of total population within observed threshold walking distance in study area. Although UC no 235 (Township-Sec-B) and UC no 232 (TownshipI) have high serviceability due to well distribution of transit stops and efficient pedestrian network, while UC no 217(Shah Kamal Clifton Colony) and UC no 154 (Kotli Peer Abdul Rehman) are completely unserved which means people living in this particular zone have

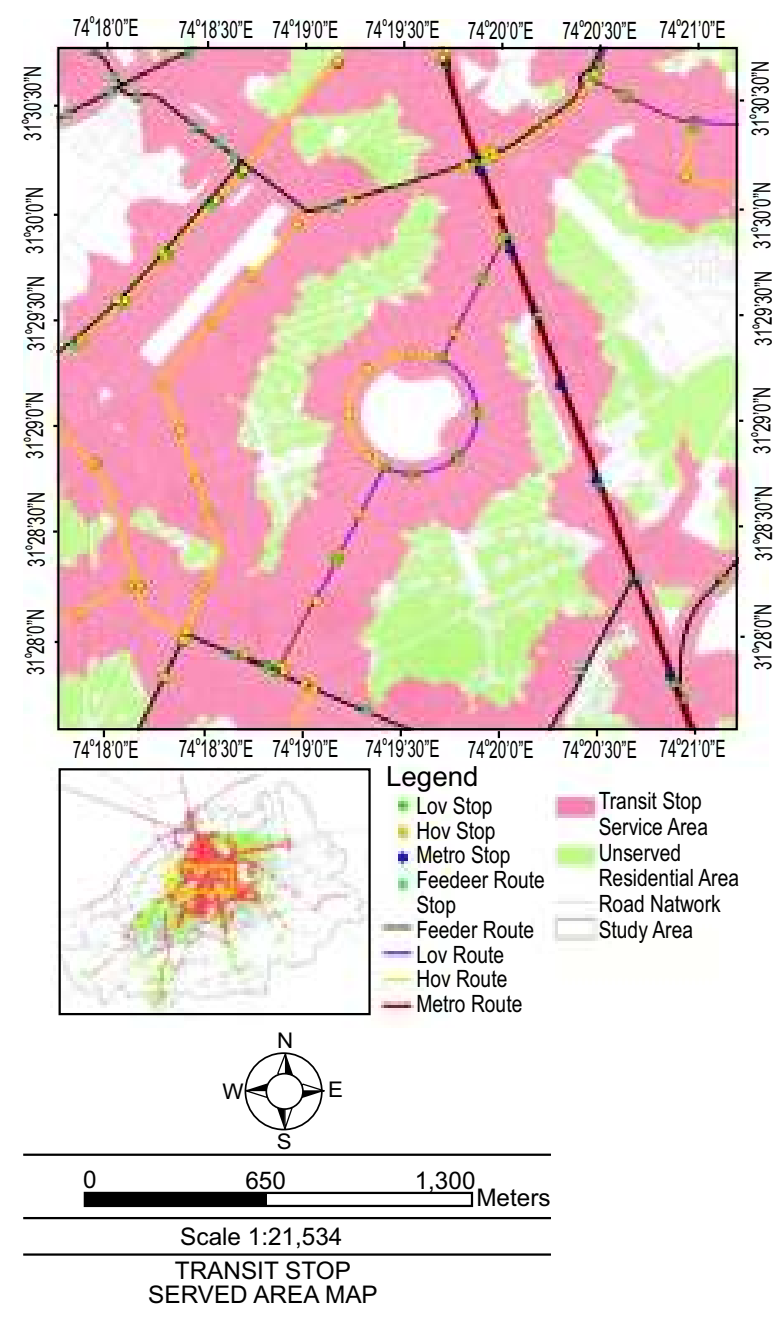

Fig. 5. Transit stops serviceability. no transit facility and may be using para transit modes or Private Transport to access nearest transit stop.

In Fig. 7, it has been observed that, serviceability of only $40 \%$ population reflecting serious lapses and gaps in existing transport infrastructure within. study area Major causes behind this poor serviceability are improper spatial distribution pattern of transit stops, absence of commuter mapping and insufficient pedestrian network. Moreover, existing transport routes are overlapping in many parts of study area while on other side there are some potential demand areas without having any sort of coverage. Consequently, there is a dire need to revise the route's alignment and stops distribution on the basis of relevant parameters in order to enhance the potential coverage. This research is helpful to propose new optimal location for transit stop and to modify the spatial location of already existed transit stop in order to enhance the efficacy of public transport.

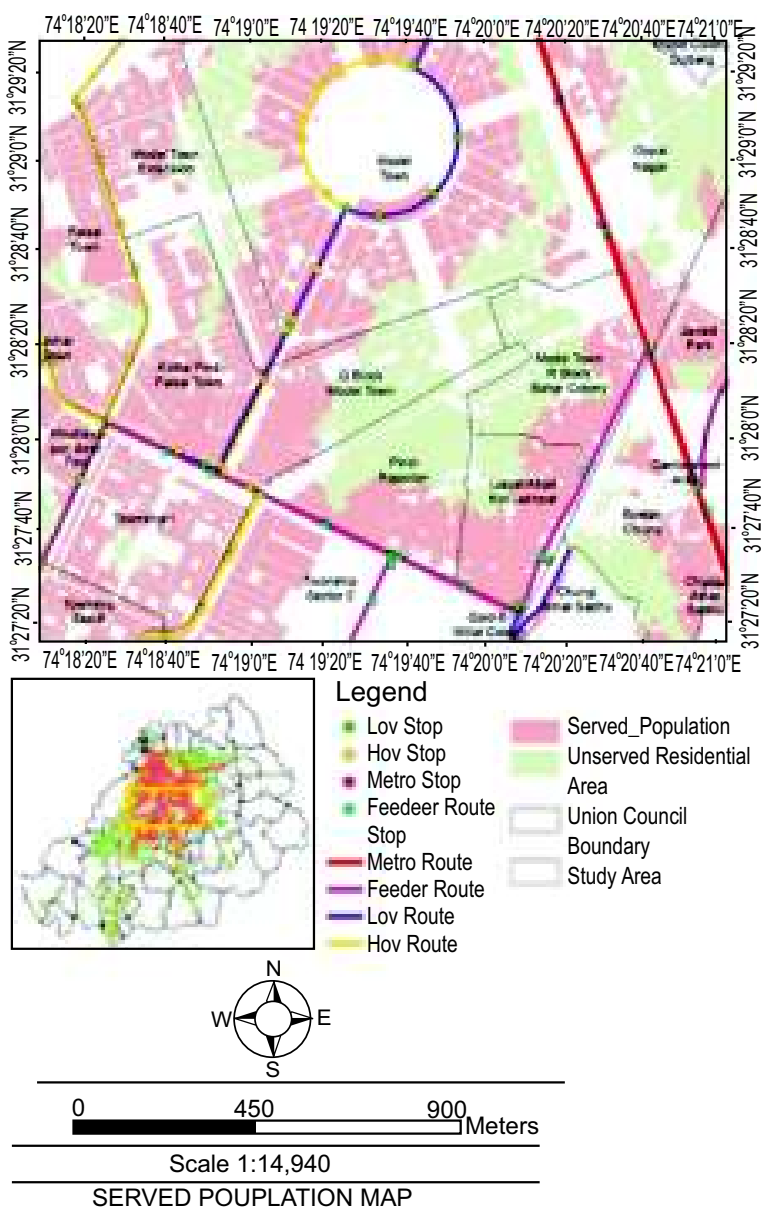

Fig. 6. Served population. 
Table 1. UC wise serviceability status in study area

\begin{tabular}{|c|c|c|c|c|c|c|c|c|c|}
\hline $\begin{array}{l}\text { UC } \\
\text { code }\end{array}$ & $\begin{array}{l}\text { Served } \\
\text { population } \\
(\%)\end{array}$ & $\begin{array}{l}\text { UC } \\
\text { code }\end{array}$ & $\begin{array}{l}\text { Served } \\
\text { population } \\
(\%)\end{array}$ & $\begin{array}{l}\text { UC } \\
\text { code }\end{array}$ & $\begin{array}{l}\text { Served } \\
\text { population } \\
(\%)\end{array}$ & $\begin{array}{l}\text { UC } \\
\text { code }\end{array}$ & $\begin{array}{l}\text { Served } \\
\text { population } \\
(\%)\end{array}$ & $\begin{array}{l}\text { Served } \\
\text { code }\end{array}$ & $\begin{array}{l}\text { UC } \\
\text { population } \\
(\%)\end{array}$ \\
\hline 009 & $65 \%$ & 063 & $87 \%$ & 107 & $57 \%$ & 163 & $16 \%$ & 220 & $34 \%$ \\
\hline 012 & $9 \%$ & 064 & $98 \%$ & 108 & $0 \%$ & 164 & $12 \%$ & 221 & $50 \%$ \\
\hline 013 & $11 \%$ & 065 & $48 \%$ & 109 & $1 \%$ & 165 & $28 \%$ & 222 & $44 \%$ \\
\hline 015 & $68 \%$ & 066 & $98 \%$ & 110 & $15 \%$ & 166 & $0 \%$ & 223 & $42 \%$ \\
\hline 016 & $81 \%$ & 067 & $1 \%$ & 111 & $38 \%$ & 168 & $43 \%$ & 224 & $78 \%$ \\
\hline 017 & $95 \%$ & 068 & $67 \%$ & 112 & $34 \%$ & 169 & $72 \%$ & 225 & $40 \%$ \\
\hline 018 & $24 \%$ & 069 & $55 \%$ & 113 & $58 \%$ & 170 & $90 \%$ & 226 & $49 \%$ \\
\hline 019 & $71 \%$ & 070 & $70 \%$ & 114 & $34 \%$ & 171 & $92 \%$ & 227 & $88 \%$ \\
\hline 020 & $54 \%$ & 071 & $9 \%$ & 115 & $29 \%$ & 172 & $99 \%$ & 228 & $50 \%$ \\
\hline 021 & $3 \%$ & 072 & $67 \%$ & 116 & $5 \%$ & 173 & $97 \%$ & 229 & $53 \%$ \\
\hline 022 & $99 \%$ & 073 & $50 \%$ & 117 & $8 \%$ & 175 & $37 \%$ & 230 & $95 \%$ \\
\hline 023 & $46 \%$ & 074 & $59 \%$ & 118 & $53 \%$ & 178 & $4 \%$ & 232 & $100 \%$ \\
\hline 024 & $27 \%$ & 075 & $65 \%$ & 119 & $9 \%$ & 182 & $8 \%$ & 233 & $93 \%$ \\
\hline 025 & $16 \%$ & 076 & $99 \%$ & 120 & $7 \%$ & 183 & $17 \%$ & 235 & $100 \%$ \\
\hline 027 & $98 \%$ & 077 & $93 \%$ & 121 & $35 \%$ & 184 & $83 \%$ & 236 & $89 \%$ \\
\hline 028 & $46 \%$ & 078 & $86 \%$ & 122 & $48 \%$ & 185 & $65 \%$ & 237 & $95 \%$ \\
\hline 029 & $37 \%$ & 079 & $93 \%$ & 123 & $49 \%$ & 186 & $89 \%$ & 238 & $96 \%$ \\
\hline 030 & $65 \%$ & 080 & $49 \%$ & 124 & $92 \%$ & 187 & $80 \%$ & 239 & $14 \%$ \\
\hline 031 & $37 \%$ & 081 & $63 \%$ & 125 & $24 \%$ & 188 & $97 \%$ & 240 & $25 \%$ \\
\hline 032 & $69 \%$ & 082 & $66 \%$ & 126 & $4 \%$ & 193 & $13 \%$ & 241 & $44 \%$ \\
\hline 033 & $98 \%$ & 083 & $98 \%$ & 128 & $44 \%$ & 194 & $9 \%$ & 242 & $28 \%$ \\
\hline 034 & $99 \%$ & 084 & $63 \%$ & 129 & $33 \%$ & 195 & $90 \%$ & 243 & $10 \%$ \\
\hline 035 & $97 \%$ & 085 & $48 \%$ & 130 & $1 \%$ & 198 & $53 \%$ & 244 & $24 \%$ \\
\hline 036 & $94 \%$ & 086 & $46 \%$ & 141 & $0 \%$ & 199 & $70 \%$ & 245 & $37 \%$ \\
\hline 037 & $99 \%$ & 087 & $0 \%$ & 142 & $62 \%$ & 200 & $39 \%$ & 246 & $17 \%$ \\
\hline 038 & $87 \%$ & 088 & $33 \%$ & 143 & $24 \%$ & 201 & $83 \%$ & 247 & $20 \%$ \\
\hline 039 & $99 \%$ & 089 & $98 \%$ & 145 & $56 \%$ & 202 & $57 \%$ & 248 & $15 \%$ \\
\hline 044 & $1 \%$ & 090 & $45 \%$ & 146 & $96 \%$ & 203 & $39 \%$ & 250 & $27 \%$ \\
\hline 045 & $22 \%$ & 091 & $85 \%$ & 147 & $74 \%$ & 204 & $0 \%$ & 251 & $69 \%$ \\
\hline 048 & $95 \%$ & 092 & $67 \%$ & 148 & $18 \%$ & 205 & $36 \%$ & 255 & $23 \%$ \\
\hline 049 & $50 \%$ & 093 & $9 \%$ & 149 & $57 \%$ & 206 & $66 \%$ & 256 & $20 \%$ \\
\hline 050 & $36 \%$ & 094 & $91 \%$ & 150 & $59 \%$ & 207 & $69 \%$ & 257 & $5 \%$ \\
\hline 051 & $48 \%$ & 095 & $81 \%$ & 151 & $14 \%$ & 208 & $77 \%$ & 258 & $0 \%$ \\
\hline 052 & $91 \%$ & 096 & $24 \%$ & 152 & $56 \%$ & 209 & $90 \%$ & 259 & $3 \%$ \\
\hline 053 & $60 \%$ & 097 & $48 \%$ & 153 & $47 \%$ & 210 & $89 \%$ & 262 & $8 \%$ \\
\hline 054 & $73 \%$ & 098 & $46 \%$ & 154 & $0 \%$ & 211 & $81 \%$ & 266 & $13 \%$ \\
\hline 055 & $25 \%$ & 099 & $19 \%$ & 155 & $30 \%$ & 212 & $72 \%$ & 267 & $4 \%$ \\
\hline 056 & $65 \%$ & 100 & $78 \%$ & 156 & $69 \%$ & 213 & $49 \%$ & 268 & $24 \%$ \\
\hline 057 & $86 \%$ & 101 & $89 \%$ & 157 & $69 \%$ & 214 & $83 \%$ & 269 & $7 \%$ \\
\hline 058 & $27 \%$ & 102 & $63 \%$ & 158 & $70 \%$ & 215 & $73 \%$ & 270 & $0 \%$ \\
\hline 059 & $19 \%$ & 103 & $19 \%$ & 159 & $0 \%$ & 216 & $2 \%$ & 271 & $65 \%$ \\
\hline 060 & $63 \%$ & 104 & $84 \%$ & 160 & $3 \%$ & 217 & $0 \%$ & 272 & $9 \%$ \\
\hline 061 & $88 \%$ & 105 & $10 \%$ & 161 & $7 \%$ & 218 & $29 \%$ & 273 & $11 \%$ \\
\hline 062 & $84 \%$ & 106 & $0 \%$ & 162 & $37 \%$ & 219 & $47 \%$ & 274 & $68 \%$ \\
\hline Total & & & $40 \%$ & & & & & & \\
\hline
\end{tabular}

In scenario 1, as the maximum walk time threshold of 8 minutes is considered across developed countries, but in this study serviceability with this walk time only provides $40 \%$ population coverage. These results are quite alarming being the metropolitan city and provincial capital. In scenario 2, threshold has been slightly increased upto 10 min either to check that any sufficient increase in serviceability would occur, but the obtained results do not provide any reasonable increment. Consequently, these results translate very serious issues regarding the Public Transport infrastructure which demand immediate attention and remediation.

\section{Conclusion and Recommendations}

This study illustrates the capability of GIS based network service area analysis to examine the deficiencies in 


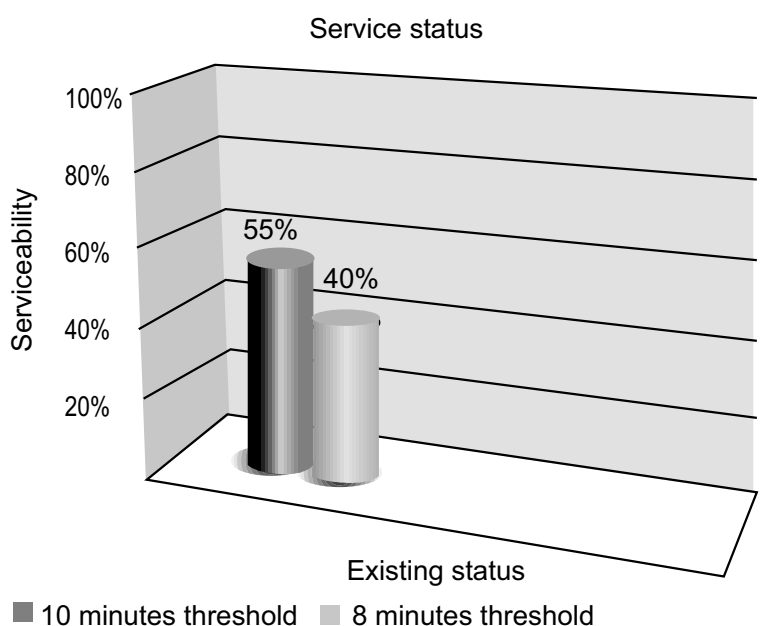

Fig. 7. Serviceability comparison in different time thresholds.

existing Public Transport network and also identifies the areas where improvement needed. There is a dire need to propose new routes along with transit stops proper distribution to improve/maximize the service ability status especially in those areas with poor/less service ability. Subsequently, a transport network having good accessibility for commuters will ultimately leads in establishing a reliable transport system and reducing the private vehicles and traffic congestion. In addition, provision of sustainable transport system will establish equity in ecology and environment across the study area.

This is the right time to make serious efforts to design a spatial decision system for sustainable integrated Urban Transport in city by keeping in view the general public issues. This may be done by conducting a comprehensive study which must incorporates the data of road geometry public demand, commuter's density, unserved pockets and growth pattern of the city. Sustainable Public Transport models of other developed cities i.e. London, Turkey, Tokyo etc. may also be followed and replicated in study area. The local government departments and other stake have to onboard to mitigate this serious challenge otherwise existing inefficient and unreliable Public Transport system will lead to big chaos in terms of huge increase in personal vehicle in city. Concerned transport agencies must organize such periodic studies at least in the major cities of Pakistan to assess the Public Transport service delivery to the people.
Conflict of Interest. The authors declare no conflict of interest.

\section{References}

Ammons, D.N. 2001. Municipal benchmarks In: Assessing Local Performance and Establishing Community Standards, Milne, Robin G., 149-163 pp., London.

Biba, S., Curtin, K.M., Manca, G. 2010. A new method for determining the population with walking access to transit. International Journal of Geographical Information Science, 24: 347-64.

Bok, J., Kwon, Y. 2016. Comparable measures of accessibility to public transport using the general transit feed specification. Sustainability, 8: 1-13.

Chai, J., Lu, Q.Y., Wang, S.Y., Lai, K.K. 2016. Analysis of road transportation energy consumption demand in China. Transportation Research Part D: Transport and Environment, 48: 112-124.

Curtis, C., Scheurer, J. 2010. Planning for sustainable accessibility: Developing tools to aid discussion and decision-making. Progress in Planning, 74: 53-106.

El-Geneidy, A.M., Tetreault, P., Surprenant-Legault, J. 2010. Pedestrian access to transit: Identifying redundancies and gaps using a variable service area analysis. Transportation Research Board $89^{\text {th }}$ Annual Meeting, 10: 8-37.

Finnis, K.K., Walton, D. 2008. Field observations to determine the influence of population size, location and individual factors on pedestrian walking speeds. Ergonomics, 51: 827-842.

Foda, M.A., Osman, A.O. 2010. Using GIS for measuring transit stop accessibility considering actual pedestrian road network. Journal of Public Transportation, 13: 23-40.

Ford, A., Barr, S., Dawson, R., James, P. 2015. Transport accessibility analysis using GIS: Assessing sustainable transport in London, ISPRS. International Journal of Geo-Information, 4: 124-149.

Foth, N., Manaugh, K., El-Geneidy, A.M. 2013. Towards equitable transit: examining transit accessibility and social need in Toronto, Canada, 1996-2006. Journal of Transport Geography, 29: 1-10.

Grengs, J. 2010. Job accessibility and the modal mismatch in Detroit. Journal of Transport Geography, 18: 42-54.

Gulhan, G., Ceylan, H. 2016. Relation Between Land 
Use and Transportation Planning in the Scope of Smart Growth Strategies: Case Study of Denizli, Turkey. In Sustainable Urbanization, http:11dx.doi. org $/ 10.5772 / 62871$

Handy, S. 2005. Smart growth and the transportationland use connection: What does the research tell us? International Regional Science Review, 28: 146-167.

Javed, M.A., Ahmad, S.R., Ahmad, A., Taj, A.A., Khan, A. 2013. Assessment of neighbourhood parks using GIS techniques in Sheikhupura city. Pakistan Journal of Science, 65: 296-302.

Lei, T.L., Church, R.L. 2010. Mapping transit-based access: integrating GIS, routes and schedules. International Journal of Geographical Information Science, 24: 283-304.

Mamun, S. 2011. Public transit accessibility and need indices: Approaches for measuring service gap, University of Connecticut, Master's Project Thesis, pp. 5-7.

Mavao, S., Witten, K., McCreanor, T., O'Sullivan, D. 2012. GIS based destination accessibility via public transit and walking in Auckland, New Zealand.
Journal of Transport Geography, 20: 15-22.

Park, S.J. 2012. Measuring public library accessibility: A case study using GIS. Library \& Information Science Research, 34: 13-21.

Qureshi, A.I., Lu, H. 2007. Urban Transport and sustainable transport Strategies: a case study of Karachi, Pakistan. Tsinghua Science \& Technology, 12: 309-317.

Saghapour, T., Moridpour, S., Thompson, R.G. 2016. Modeling access to public transport in urban areas. Journal of Advanced Transportation, 50: 17851801.

Van, W.B. 2011. Evaluating the impact of land use on travel behaviour: the environment versus accessibility. Journal of Transport Geography, 6: 15301533.

Wang, J. 2011. Appraisal of factors influencing public transport patronage. NZ Transport Agency Research Report no. 434. 176 pp.

Wong, J.C. 2012. Use of the General Transit Feed Specification (GTFS) in Transit Performance Measurement. Ph.D. Thesis, 83 pp., Georgia Institute of Technology. 